\title{
Measurement and Path Selection of Rural Development Level in Enclave Areas: A Case Study of Jingyuan County, Gansu Province
}

\author{
Jianwu Qi 1,2 (D), Wei Li $^{1,2, *}$, Zongxiang Wang ${ }^{1,2}$ and Haozhou Fang ${ }^{1,2}$ \\ 1 College of Geography and Environmental Science, Northwest Normal University, Lanzhou 730070, China; \\ qijianwu715@163.com (J.Q.); wzx990128@163.com (Z.W.); fhaozhou@126.com (H.F.) \\ 2 Institute of Urban Planning and Tourism Landscape Design, Northwest Normal University, \\ Lanzhou 730070, China \\ * Correspondence: Lw_nwnu@163.com; Tel.: +86-184-1995-0756
}

Citation: Qi, J.; Li, W.; Wang, Z.; Fang, H. Measurement and Path Selection of Rural Development Level in Enclave Areas: A Case Study of Jingyuan County, Gansu Province. Sustainability 2021, 13, 9904. https:// doi.org/10.3390/su13179904

Academic Editors: Jean-Pierre Gueyie and Francesco Caracciolo

Received: 9 August 2021

Accepted: 31 August 2021

Published: 3 September 2021

Publisher's Note: MDPI stays neutral with regard to jurisdictional claims in published maps and institutional affiliations.

Copyright: (c) 2021 by the authors. Licensee MDPI, Basel, Switzerland. This article is an open access article distributed under the terms and conditions of the Creative Commons Attribution (CC BY) license (https:// creativecommons.org/licenses/by/ $4.0 /)$.

\begin{abstract}
The development of rural areas is a significant component in social and economic activities. It is very important for optimizing the allocation of rural production and living factors, promoting the integration of urban and rural areas and sustainable development to identify the characteristics and main types of regional rural development. In this paper, 169 villages in Jingyuan County were selected as the research object, and the evaluation index system of rural development level was constructed from the perspective of "Factor-structure-function". The rural development level and spatial structure characteristics of Jingyuan County were analyzed by using rural development index, regional function index, nearest neighbor index, and exploratory spatial data analysis, and the types and specific paths of rural development were determined. The results showed the following: Rural development of Jingyuan County is at a low level, which is characterized by "high in the south and low in the north". The level of rural development shows significant spatial dependence in the global space, and the spatial agglomeration characteristics are obvious, which are manifested as strong agglomeration dominated by resource endowment and cultural function and weak agglomeration dominated by production function and location relationship. The local space is characterized by stable high value and high value $(\mathrm{H}-\mathrm{H})$, low value and low value (L-L) bidirectional agglomeration. According to the spatial characteristics of the rural development level, the " $4+10+6+2$ " system of rural development type identification in Jingyuan County was constructed, and finally it was determined that policy leading and characteristic protection are the dominant types of rural development. Based on this, this paper put forward specific paths and development models of different types of rural development in Jingyuan County from seven dimensions: industry, population, land, tourism, space, culture and ecology, so as to provide ideas and references for the integration of urban and rural areas, the implementation of rural revitalization strategy, and sustainable development in the western poverty-stricken areas.
\end{abstract}

Keywords: rural development level; regional function; type recognition; development path; enclave area; Jingyuan County

\section{Introduction}

Rural areas are complex regional systems formed under the mutual connection and interaction of society, economy, resources, and environment [1]. Under the influence of external environments and internal factors, the evolution of the rural system shows different characteristics due to the reorganization of factors, structure, and function [2]. In 2017, the report of the Nineteenth National Congress of the Communist Party of China proposed to solve the imbalance between urban and rural development, specifically insufficient rural development, through the implementation of the Rural Revitalization Strategy, and to complement the rural short board of building a well-off society in an all-round way [2]. In 
this context, the focus of rural sustainable development has gradually shifted to promoting the transformation of the integration and replacement of urban and rural resources by top-level design. The top-level design of rural development is realized through the establishment of an urban-rural integration development system and mechanism and the backflow of external resource elements [3]. The premise of the urban-rural integration mechanism and the backflow of external resource elements are to clarify the current situation of rural development and reasonably evaluate the level of rural development. Rural development is an important constraint factor for regional sustainable development, rapid economic transformation, and balanced allocation of resources in China. Research on rural development level, rural type, and development path is necessary to accurately grasp the development trend and internal needs of rural areas, formulate scientific development strategies, and promote the effective implementation of rural revitalization strategies.

As a special regional unit, the enclave-type areas are separated by the administrative function integration of political management and the spatial status quo hindered by the environment, which makes the rural settlement space present regional, structural, and special characteristics [4]. The functional separation of enclave-type areas under administrative divisions and spatial layout makes the rural spatial structure scattered, the functional structure unitary, and the rural development vigor weak [5]. The enclave area is a region with a special shape, function, and grade in a northwest arid area and the Gansu province. The measurement and classification of rural development level in enclave-type areas are of great significance to the integration of village resources, industrial revitalization, cultural integration, and ecological maintenance under the influence of administrative divisions and natural environment factors. It is conducive to promoting the layout planning of villages and the construction of ecological civilization of well-off villages, reducing the spatial differences of rural development in Gansu Province, and promoting the sustainable development of human settlements, urban and rural integration, and regional coordination. The key issues of rural research in enclave-type areas are to clarify what types of development exist in space and what the formation factors of spatial differences in rural development levels are. The core goal of the study was to scientifically measure the level of rural development in the enclave areas, explore the development characteristics of different types of villages in the enclave areas unit, and determine the specific path of rural sustainable development according to the actual development of different types of villages.

\section{Literature Review}

The evaluation of rural development level is a re-cognition of the process of production development, environmental improvement, and cultural inheritance in the specific rural regional system [1]. The core of rural geography research from an international perspective is rurality [6]. Cloke et al. first proposed to measure the state of rural development in a region through rurality [6-8]. Based on recent advances in rural geography, Woods et al. proposed that rurality is a rural "character" experienced and expressed by rural residents and immigrants, farmers, landowners, workers, travelers, leisure tourists, policymakers, media, and academic researchers [9,10]. From the perspective of the evolution of the theory of rural studies, the rural areas have experienced the transformation from the functional perspective to the political and economic perspective and the social construction perspective [6-10]. In the functional perspective of the 1970s, rural space was determined by rural functional characteristics. From the perspective of political economy in the 1980s, rural areas were defined as the product of social, economic, and political processes. From the perspective of social construction in the 1990s, it is proposed that rurality should be reflected in the social, cultural, and moral values of rural areas [11]. Since the 21st century, the perspective of rural studies has gradually shifted to "cultural ecology", and the proposal of the "Triple space model of rural" has further expanded the theoretical horizon of rural studies [1,2].

The rural regional system is a rural spatial system with a certain structure, function, and interregional connection under the mutual connection and interaction of humanities, 
economy, resources, and environment $[8,12]$. From the current research on rural development, the themes focus on rural connotation and rurality $[7,13,14]$, rural development type classification [15-18], rurality evaluation [19-22], rural transformation and reconstruction $[17,18,23]$, rural construction, and revitalization [1,2]. Halfacree et al. elaborated the specific connotation of rural in four dimensions: the descriptive definition, the sociocultural definition, the rural as geographical area, and the rural as the social representation reproduction [24]. Woods proposed that the formation and evolution of rural areas can be explained appropriately only by taking rural areas as the representation of society [10], and the differences between small towns in rural areas, outskirts of new cities, peripheral communities of cities, and urban-rural fringe areas can be compared. Liu Yansui et al. explored rural development from different perspectives, scales, and spaces in China from the aspects of the rural regional system $[3,25,26]$, rural development types and evaluation [16,17], rural transformation and reconstruction $[2,18,27]$, rural revitalization theory and methods, land use renovation, and transformation [23,28].

The research content mainly focuses on the evaluation of rurality and the analysis of influencing factors, while the measurement of the rural development level within the micro unit is less. The existing research mainly focuses on the identification of rural development types [29,30], the construction of rural evaluation indicators [21,25,31], the spatial and temporal differentiation characteristics of rurality [13,32,33], and the evaluation of rural development and transformation. Zhang Xiaolin et al. conducted a long-term exploration on the interpretation of the concept, classification, evaluation method, and index system of rurality, evaluated the rurality of different scales and regions in Jiangsu Province, and explored the evolution and influence mechanism of the rural spatial pattern [34-36]. From the perspective of research methods, qualitative methods have long dominated. It mainly includes semi-structured interviews, focus groups, ethnography and participant observation, and literature analysis. Qualitative methods are widely used in British rural research [37-39]. Quantitative methods are widely used in the United States, Europe, Australia, China, and other regions [21,29,40-42]. They mainly include the SOFM network

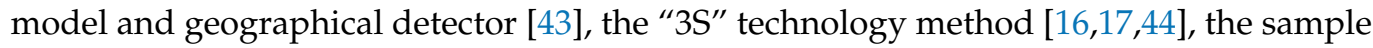
band research method [22,45], the network analysis method, and the improved entropy method [21]. Madsen et al. proposed that a combination of qualitative and quantitative methods should be integrated to help strengthen the understanding of rural space use in both developing and developed countries [38,46].

From the perspective of research scale and regional selection, most studies focus on Europe, North America, Northeast Asia, and developed countries [5,13,38,41] such as the United States, France, South Korea, and Japan [22,47-50]. Rural studies in China are mostly based on regional, provincial, and county scales [20,44,51,52]. In recent years, the scale of rural research has gradually focused on the micro field, paying more attention to the micro regional space and specific groups of rural residents $[28,36,53,54]$. For example, Gulumser et al. used principal component analysis and cluster analysis methods to classify the regions with similar core characteristics on the basis of dimensionality reduction $[1,55]$. Based on the town scale, Long Dongping et al. evaluated the rural development level of Gaoling County in Shaanxi Province in different periods [56], and explored the driving mechanism of rural development by using multiple linear regression analysis.

There are significant research results on rural development at home and abroad, but from the perspective of research topics, they do not answer the question of where special geographical units should go [7,42]. Too much attention has been paid to the definition of rural connotation, the division of rural types, and the construction of evaluation indicators, lacking multi-perspective, multi-system, and multi-scale rural classification methods $[1,9,34]$. Most studies focus more on revealing the overall characteristics of rural development from a macro-regional perspective, and lack differentiated analysis of rural development under the influence of different structures, factors, and functions from a micro perspective [57]. Rural development constitutes all the behavior of residents in daily life, and the rural space has the functions of production, life, ecology, and culture. The 
measurement index of the rural development level should fully consider the function of rural residents' daily behavior [35]. Based on this, this paper selected the enclave-type regional countryside as the object, from the perspective of "factor-structure-function" correlation, combined with the actual rural development in Jingyuan County, Gansu Province, to construct the measurement index system of the development level of the enclave-type regional countryside. Through the combination of qualitative and quantitative methods, the level and type of rural development in Jingyuan County were explored, and the specific path of rural development was formulated so as to provide a scientific basis and theoretical reference for the rural transformation and development in the western poverty-stricken areas from the micro perspective and the implementation of a rural revitalization strategy.

\section{Study Area and Data}

\subsection{Study Area Overview}

Jingyuan County is located in the central part of the Gansu Province in the Yellow River Basin, in the hinterland of Baiyin, which is a typical loess plateau gully area. Jingyuan County is a typical enclave area, in which the Pingchuan District of Baiyin City is embedded. The county area is divided into two parts, forming the southern main area and the northern enclave area (Figure 1). The administrative residence of the county is Wulan Town. In 2020, the total land area of the county was $5809.4 \mathrm{~km}^{2}$, which now covers 18 towns, 177 administrative villages, and 15 communities, with a total population of 503,600, of which 342,900 are agricultural people. The town where the county is located and the other two towns in the whole county are located in the main area of the south, while the northern enclave area includes eight townships, namely Xinglong Township, Shuanglong Township, Shimen Township, and Jing'an Township, commonly known as the "North Eight Township". Jingyuan County is the gateway node of the economic belt along the Yellow River, the political, economic, and cultural link of the region along the Yellow River, and also an important bearing city for industrial development.

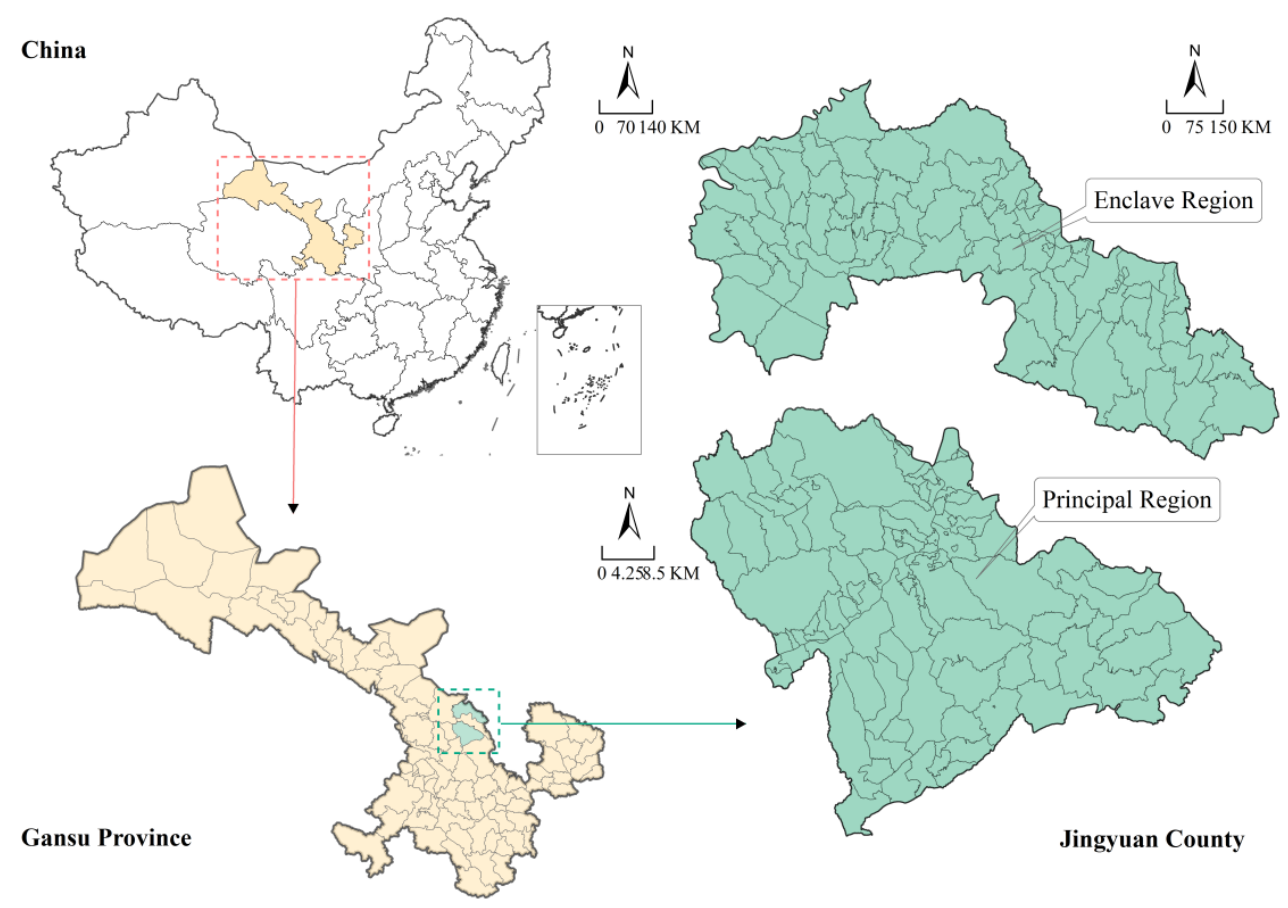

Figure 1. Jingyuan County overview map.

The large income gap between urban and rural residents, the aggravation of rural population aging, and the serious labor burden are the main factors restricting the rural development of Jingyuan County. In 2020, the per capita disposable income of rural 
residents in the county was 9555 Yuan, an increase of $8.8 \%$ compared with the previous year. The per capita disposable income of urban residents is 25,212 Yuan, an increase of $7.36 \%$ over the previous year. The proportion of the elderly population (over 60 years old) in each township is greater than $10 \%$. The poor foundation of rural development in Jingyuan County is the main object of poverty alleviation in the province. At the same time, as a typical enclave area, the special administrative division adjustment in the historical period has formed a very representative enclave rural spatial pattern. Therefore, 169 administrative villages in the region (except some farms and merged villages) were selected as the research objects.

\subsection{Data Sources}

The data involved in the study include: (1) National economic statistics. Rural population, per capita GDP, per capita disposable income of rural residents, industrial data, per capita food production, and other data were derived from the statistical yearbook of Jingyuan County in 2020, the bulletin of national economic and social development and rural statistical departments. (2) Village survey data. The data of household registration population, floating population, permanent residents over 60 years old, the number and grade of intangible cultural heritage, cultural heritage coordinate data, village location relationship (with the central city, town, large industrial, and mining enterprises) were all derived from the village questionnaire and interview data of Jingyuan County's territorial spatial planning (2019-2035). (3) Vector raster data. The potential of Agricultural resources, farmland concentration connectivity, the area urban and rural construction land, the degree of vegetation cover, and the data of land use were all derived from the third land use survey data in 2020 and were processed and corrected by collage, clipping, and vectorization; eventually, spatial data were finally formed. Jingyuan County DEM data, vegetation cover data, and administrative division boundary data were all derived from the Chinese Academy of Sciences Computer Network Information Center Science Data Center Geospatial Data Cloud Platform (http:/ / www.gscloud.cn/ accessed on 21 August 2021).

\section{Research Ideas and Methods}

\subsection{Research Ideas}

Under the guidance of natural resources, social economy, and policy conditions, rural areas form different spatial structures $[7,14]$. There are great differences in resource supply and service level under different spatial structures, which lead to the spatial differentiation of the rural development level, and thus form production, life, ecology and cultural functions $[1,34,35]$. The rural regional system is an open system with certain functions and structures, which is composed of natural environment, resource endowment, location conditions, cultural customs, and other factors within a specific rural area [2]. The rural development system is based on the rural regional system as the basic unit, which divides the rural internal regeneration and external development system from the subject and object of rural development $[1,6,13,42,49]$. It constitutes multi-factor, multi-scale, multi-directional external development conditions constraints, as well as an internal development matrix balance to promote rural dynamic sustainable development. The rural development system is an important carrier for interpreting the role replacement of different elements, structures, and functions in the process of rural development $[31,54]$, such as social capital, resource conditions, economic foundation, cultural context, industrial structure, and regional functions. Its core links were set as "the role of people in the relationship between economy, resources and space" and "what functions space bears in the process of rural development elements and structural evolution" [2,35]. Finally, through the multidimensional correlation of "elements-structure-function", a rural development system with diverse scales, complex structures, and obvious functions was formed (Figure 2). 


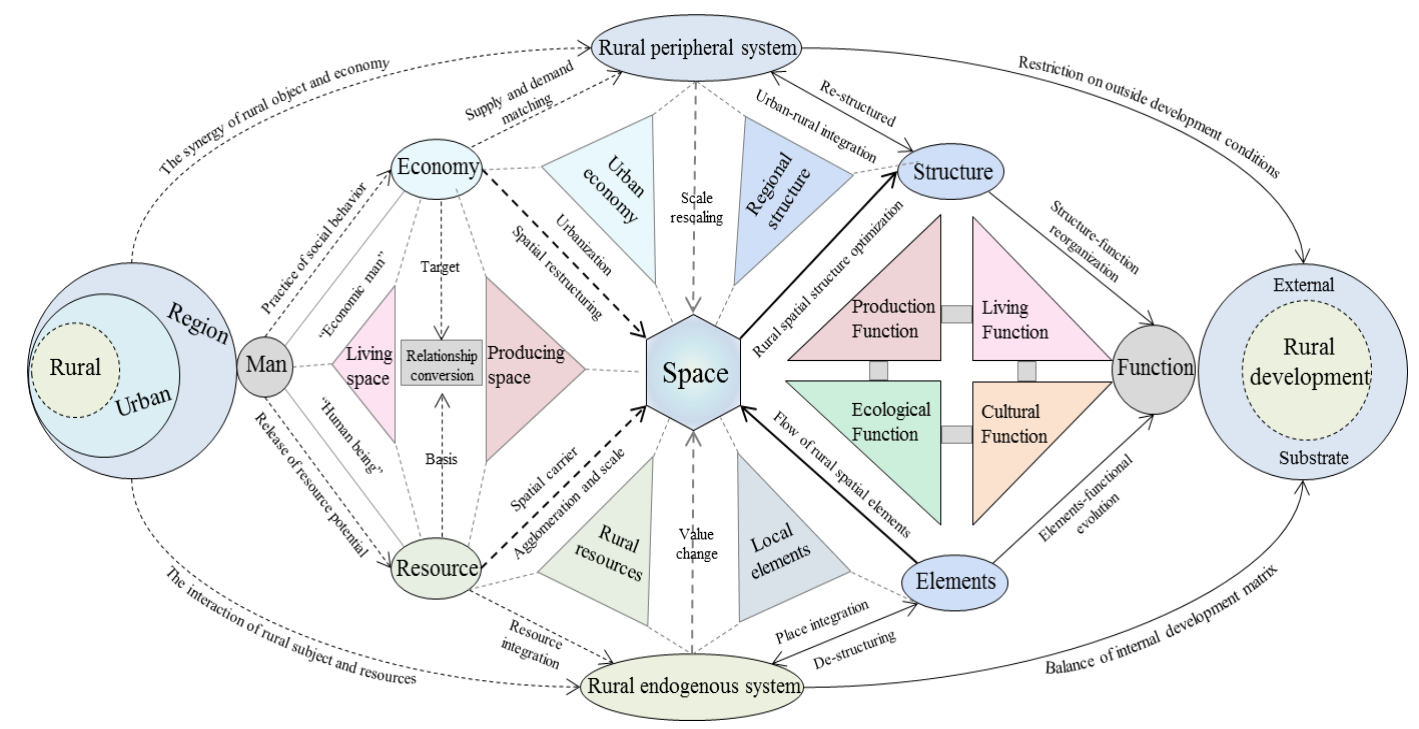

Figure 2. The rural development system from the perspective of "factor-structure-function".

The rural development system from the perspective of "factor-structure-function" correlation highlights the two core relationships in the process of rural development [1]. The first is the integration and reconstruction of the "economic man" and "natural man" in space. The second is the evolution and reorganization of rural elements, structure, and function in the process of spatial integration. Integration and reconstruction emphasize the supply and demand matching of resource agglomeration and large-scale utilization and economic development, and integration emphasizes the potential release and spatial utilization of rural resources in rural endogenous system [37,42,58]. Reconstruction of man-made social practice and urban economic coordination focuses on the rural periphery system $[18,23,45]$. It necessitates evolution and restructuring focus on the association and interaction of development factors, industrial structure, and spatial functions (production, life, ecology and culture) in rural space, and integrating and diversifying resource factors, economic structure, and spatial functions in the rural regional system through spatial carrying $[19,39]$. As an important part of the rural development system, the resource elements combine the economic structure with the spatial function by means of the flow of the spatial elements and the structural optimization, and promote the internal transformation of rural development elements, structure, and function $[3,33,59,60]$. The elements of rural resources constitute the unique economic structure of rural areas, and the adjustment and optimization of economic structure determine the differences and particularities of rural functions.

Referring to the related achievements of the measurement of rural development level at home and abroad, the idea framework of rural development level measurement in the enclave region was determined (Figure 3). Jingyuan County, as a special enclave area in northwest arid area, has its rural development affected by policy conditions, administrative divisions, topography, industrial adjustment, and other factors. Therefore, the measurement of rural development level should be based on empirical investigation, and it is necessary to have an in-depth understanding of rural development status and rural regional characteristics in Jingyuan County. The study is mainly divided into four parts. First, we determine the function of the rural development level and the process of correction and evaluation to accurately understand the rural development of Jingyuan County through the between factors, structure, and functions. Secondly, we determine the evaluation method and index system, scientifically calculate the rural development index, and analyze its spatial differentiation characteristics. Next, by measuring the rural development index and related data, we determine the rural development type identification system, and 
accurately identify the rural dominant type. Finally, the specific path and mode of different rural development types are determined.

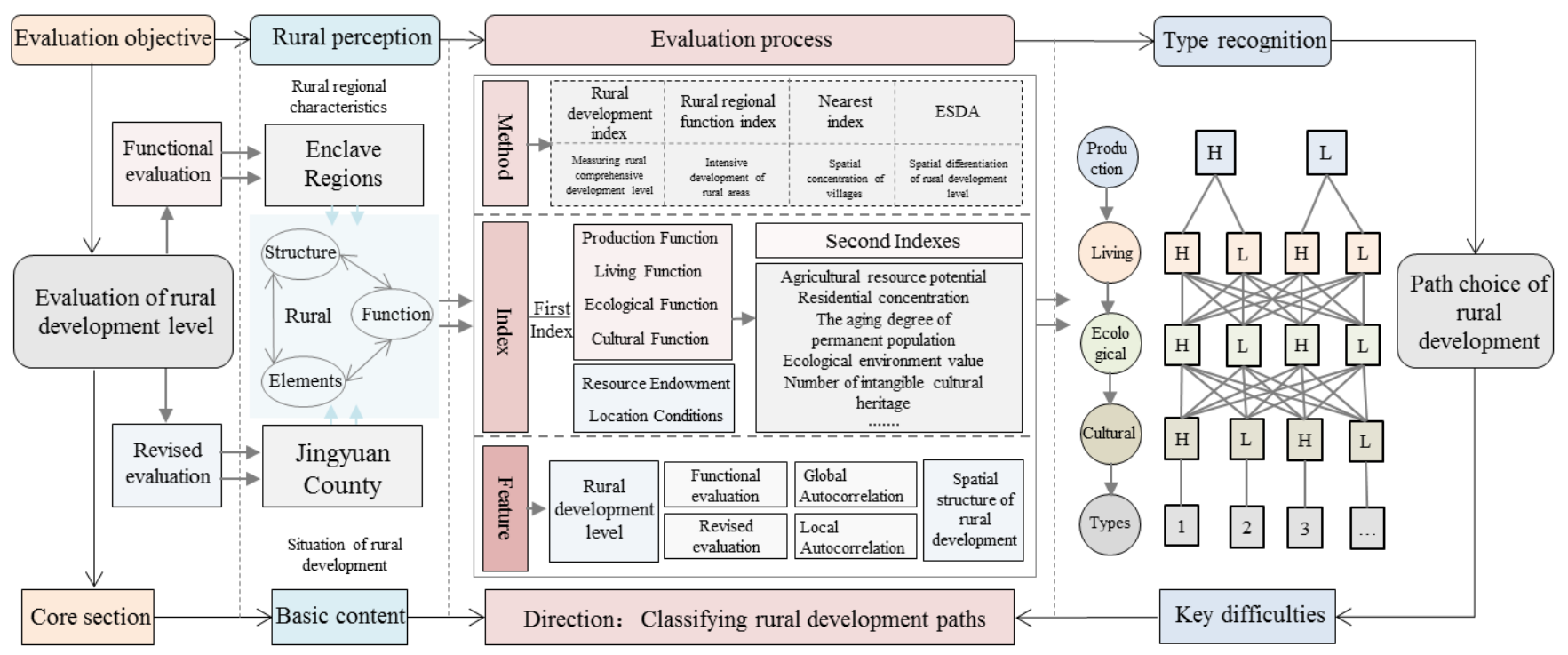

Figure 3. Evaluation framework of rural development level in enclave areas.

\subsection{Evaluation Index System of Rural Development Level}

Following the principles of systematic, scientific, regional, directional, and practical index construction $[58,61]$, combined with the actual situation of rural development in Jingyuan County from the perspective of "factor-structure-function" correlation, 11 indexes were selected as the evaluation index of rural development level function from the dimensions of production function, life function, ecological function, and cultural function $[3,25,31,62]$. From the dimensions of natural endowment and location conditions, five indexes were selected as the revised evaluation indexes of rural development level in enclave regions. Sixteen indicators such as agricultural resource potential, farmland concentration, residential land area, resident population aging degree, village ecological environment value, and spatial relationship between village and central urban area were selected as the evaluation index system of rural development level (Table 1).

\subsection{Evaluation Index System of Rural Development Level \\ 4.3.1. Rural Development Index}

The countryside is an open, pluralistic, and complex giant system. Rural development is affected by many factors such as production, life, ecology, and culture. Based on the comprehensive measurement of rurality and rural development by Liu Yansui et al. [1,2], this study constructed the rural development index to measure the comprehensive level of rural development in enclave-type regions [26,48]. The calculation of rural development index includes standardized processing of index data, the determination of index weight, and multi-index comprehensive evaluation. The specific calculation process is as follows. 
Table 1. Evaluation index system of rural development level in enclave regions.

\begin{tabular}{|c|c|c|c|c|c|}
\hline Target & First Grade Indexes & Second Indexes & Calculation Method and Explanation & Weight & Properties \\
\hline \multirow{9}{*}{ Functional evaluation } & \multirow{2}{*}{ Production Function } & Potential of agricultural resources & Weighted sum of farmland scale of each quality level & 0.0131 & Positive \\
\hline & & Concentration degree of rural land & Calculation of concentrated connectivity index & 0.0127 & Positive \\
\hline & \multirow{3}{*}{ Living Function } & Area of residential land & Total area of rural and urban construction land & 0.0121 & Positive \\
\hline & & Residential concentration & Calculation of nearest neighbor index & 0.0165 & Positive \\
\hline & & The aging degree of permanent population & $\begin{array}{l}\text { Proportion of permanent population over } 60 \text { years of age to } \\
\text { total permanent population }\end{array}$ & 0.2042 & Negative \\
\hline & \multirow{2}{*}{ Ecological Function } & Ecological environment value & Vegetation coverage (calculated by remote sensing image) & 0.0196 & Positive \\
\hline & & Value of natural landscape & Landscape index (calculated by land use data) & 0.0234 & Positive \\
\hline & \multirow[t]{2}{*}{ Cultural Function } & Number of intangible cultural heritage & $\begin{array}{l}\text { Weighted sum of intangible cultural heritage at county level } \\
\text { and above }\end{array}$ & 0.0103 & Positive \\
\hline & & Number of material cultural heritage & Weighted sum of various cultural heritage levels & 0.0085 & Positive \\
\hline \multirow{5}{*}{ Revised evaluation } & \multirow{2}{*}{ Resource Endowment } & Ratio of flat land to village area & Proportion of area below 8 degree terrain slope to village area & 0.0224 & Positive \\
\hline & & Ratio of available land to total area & Proportion of available land area to village area & 0.0258 & Positive \\
\hline & \multirow{3}{*}{ Location Conditions } & Spatial relationship with central city & Includes (1), Adjoin (0), Separate $(-1)$ & 0.0845 & Negative \\
\hline & & Spatial relationship with town & Includes (1), Adjoin (0), Separate $(-1)$ & 0.0353 & Negative \\
\hline & & $\begin{array}{c}\text { Relations with large-scale industrial and } \\
\text { mining enterprises }\end{array}$ & Includes (1), Adjoin (0), Separate $(-1)$ & 0.4294 & Negative \\
\hline
\end{tabular}


(1) Data standardization. The difference of evaluation indexes directly affects the evaluation results of rural development level. The purpose of standardized data processing is to eliminate the impact of different dimensions on the evaluation results [56], so as to ensure that the evaluation results are more objective. The calculation formula is as follows:

Positive indicators:

$$
I_{a}^{q}=\frac{O_{a}^{q}-O_{\min }}{O_{\max }-O_{\min }}
$$

Negative indicators:

$$
I_{a}^{q}=\frac{O_{\max }-O_{a}^{q}}{O_{\max }-O_{\min }}
$$

In the formula, $I_{a}^{q}$ is the standardized value of the $q$ index of the village $a, a$ is the number of villages, $a \in[1,169]$. $O_{a}^{q}$ is the original data value of the $q$ index of the village $a$, obtained by the calculation method of each index in the evaluation index system. $O_{\max }$ is the maximum of the $q$ index. $O_{\text {min }}$ is the minimum of the $q$ index.

(2) Indicator empowerment. The index weight of rural development level is determined by the entropy method to overcome the calculation error caused by subjective judgment. The calculation formula is as follows:

$$
\omega_{q}=\frac{1-\epsilon_{q}}{\sum_{q=1}^{X}\left(1-\epsilon_{q}\right)}
$$

In the formula, $\omega_{q}$ is the weight of $q$ index. $X$ is the number of different indexes, $X \in[1,16] . \epsilon_{q}$ is the entropy value of the $q$ index $[30,63]$.

(3) Multi-index comprehensive evaluation. The calculation of rural development index is based on the standardization of index value. Through the weighted superposition of index weight and standardization value, the production level index, living level index, ecological level index, cultural level index, natural endowment, and location condition were calculated. The calculation formula is as follows:

$$
R D I_{a}^{p}=\sum_{q=1}^{X}\left(\omega_{q} \times I_{a}^{q}\right)(q=1,2, \cdots, X)
$$

In the formula, $R D I_{a}^{p}$ is the rural development index of the $p$ function of village $a$, and $p$ represents the dimensions of production, life, ecology, culture, natural endowment, and location conditions. $\omega_{q}$ is the weight of the evaluation index.

\subsubsection{Rural Regional Function Index}

The rural regional function index plays an important role in improving the level of rural development and determining the direction of village development to scientifically identify regional functions and put forward the differentiated promotion path of village development in different functional areas. Referring to the identification method of rural development function types of Long Hualou et al. $[3,17,18,26]$, the rural regional function index was constructed. In general, regional functions promote the formation of the spiritual core of regional rural development and promote regional sustainable development. The calculation formula is as follows:

$$
R F I_{a}=\frac{R D I_{a}^{p}}{M_{p}+S_{p}}
$$

In the formula, RFI is the regional function index for village $a . R D I_{a}^{p}$ is the rural development index of the $p$ function of village $a . M_{p}$ and $S_{p}$ are the mean and standard deviation of the $p$-function rural development index of all villages. 


\subsubsection{Nearest Neighbor Index}

Abstracting different villages as spatial points, villages in Jingyuan County present three spatial distribution patterns: discrete, random, and agglomeration [52]. The nearest index was used to identify the agglomeration degree of rural residential areas in Jingyuan County, and the results showed the mutual proximity of rural residential areas in geographical space. The calculation formula is as follows:

$$
R=\bar{r} / \bar{r}_{i}
$$

In the formula, $r$ is the average observation distance. $r_{i}$ is the expected average distance. $R$ is the nearest index. When $R>1$, the village settlements in Jingyuan County show uniform or discrete distribution in space. When $R<1$, it shows agglomeration distribution in space. When $R=1$, the village settlements are randomly distributed in space.

\subsubsection{Exploratory Spatial Data Analysis (ESDA)}

ESDA is a spatial visualization algorithm based on mathematical statistics and graphic expression technology to obtain the attribute characteristics of the research object through spatial data analysis [55]. ESDA, also known as exploratory spatial data analysis, mainly includes the calculation of global Moran's I and local $G_{a}^{*}$ statistics [36,44,52]. The former mainly describes the spatial difference and global correlation of rural development level, and the latter was used to identify the high-value area and low-value area of rural development level, and then identify the cold and hot areas of rural development.

1. Global Moran's I calculation formula is as follows:

$$
I=\frac{\sum_{a=1}^{n} \sum_{b=1}^{m} w_{a b}\left(R F I_{a}-\overline{R F I}\right)\left(R F I_{b}-\overline{R F I}\right)}{s^{2} \sum_{a=1}^{n} \sum_{b=1}^{m} w_{a b}}
$$

In the formula, $m$ and $n$ are the number of village units. $R F I_{a}$ is the regional function index of village $a . \overline{R F I}$ represents the average value of rural regional function index in the village unit. $s$ represents the variance of $R F I_{a}$ and mean. $w_{a b}$ is the spatial weight created by the nearest neighbor rule [23,52]. Moran's $I$ is determined by the $E(I)$ value under the Free State. When the significance level is given, Moran's $I>0$; it means that the high or low value areas of rural development level are similar in space. Moran's $I<0$ indicates that the rural development level has a strong spatial difference [36].

2. Local $G_{a}^{*}$ statistics. The calculation formula is as follows:

$$
G_{a}^{*}(d)=\frac{\sum_{a=1}^{n} w_{a b} \times R F I_{a}}{\sum_{a=1}^{n} R D I_{a}}
$$

where $R F I_{a}$ represents the observed value of village $a$. If $G_{a}^{*}>0$, the rural development level of village $a$ is high, which is a hot spot [52]. If $G_{a}^{*}<0$, the rural development level of village $a$ is low, which is a cold spot area.

\section{Results Analysis}

\subsection{Characteristics of Rural Development Level in Enclave Areas}

\subsubsection{Rural Development Level under Functional Evaluation}

The level of rural development dominated by production function was high in the north and low in the south (Figure 4). The production function in the northern enclave was low, with an average of 0.06 . The range of production function was 0.19 . The high value area accounted for $8.13 \%$ of the northern villages, mainly distributed in Yihe Village, Nantan Village, Jingtan Village, Dongxing Village, and Tangzhuang Village, etc., while the low value area accounted for $18.60 \%$, mainly distributed in Shimen Village, Anwei Village, Beitan Town, Liangyao Village, Huaxian Village, and Dongsheng Village, etc. The production 
function of the southern body region was at a low level, with an average of 0.06 . The development of rural area in the south was mainly dominated by low-level development. Relatively high values accounted for $31.39 \%$ of the southern villages, which were mainly distributed in Chaoyang Village of Santan Town, Dongwan Village of Dongwan Town, and Shengli Village of Mitan Town. Lower values accounted for $51.16 \%$ of the southern villages, which were mainly distributed in Fanyao Village of Liuchuan Town, Wujiadachuan Village of Mitan Town, Yandong Village of Wulan Town, and Jiaya Village of Gaowan Town.
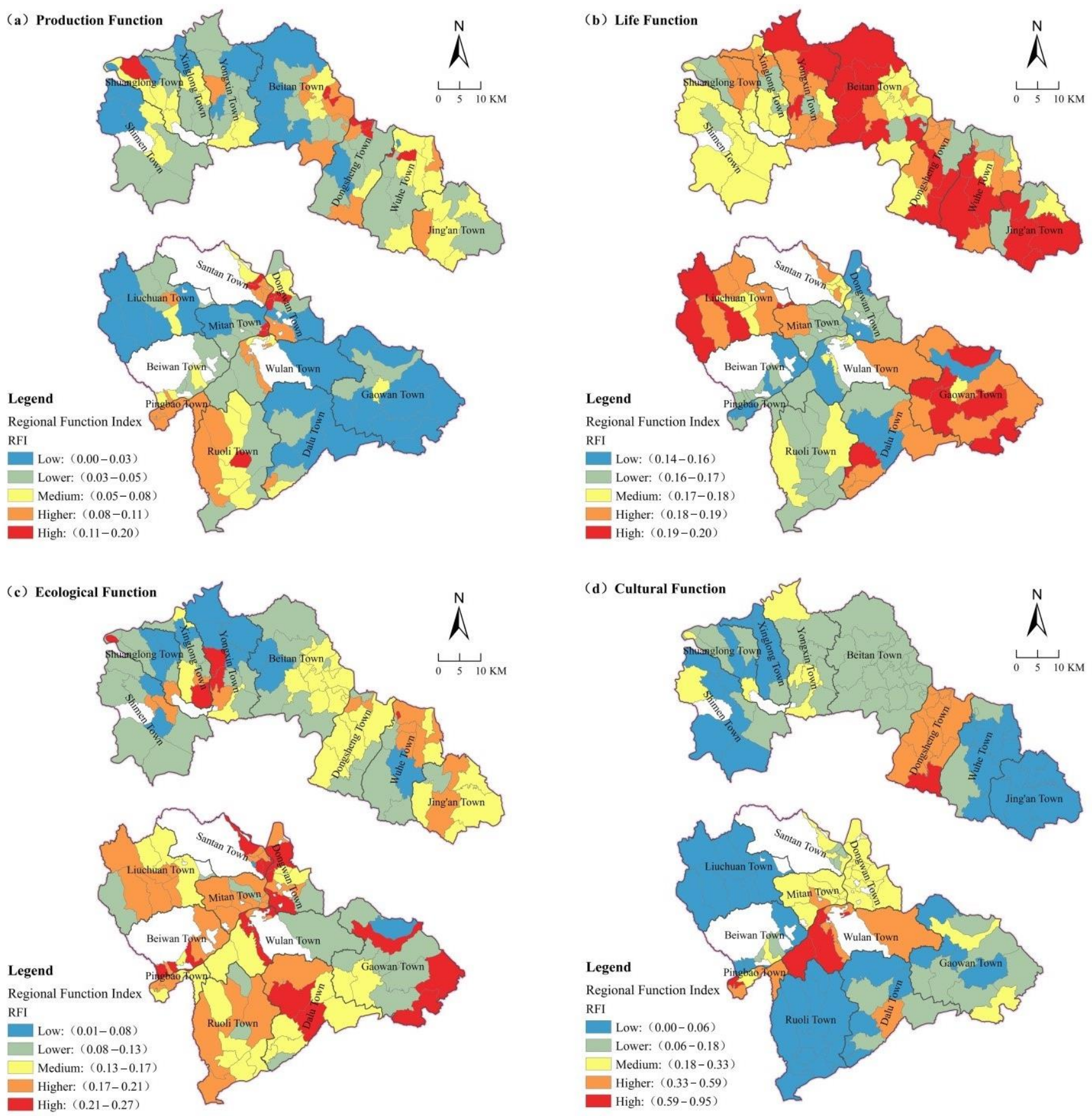

Figure 4. Rural development level under functional evaluation.

The functional living index was calculated by the size of settlements, the village population, and the aging degree of permanent residents. The village population and the aging degree of permanent residents as negative indicators are important factors to control the change of rural life development level. The weights of the above factors were 0.07 
and 0.20 respectively, indicating that the greater the functional living index evaluated by the two indicators, the lower the level of rural development. It is directly reflected in the figure that the villages with higher values accounted for $17.75 \%$ and $24.85 \%$ of the total number of villages, indicating that the rural living standards of Jingyuan County are at the middle and low level. The low-level area of rural development was mainly distributed in northern enclaves such as Tianshui Village in Beitan Town, Xiaoyuan Village in Dongsheng Township, Jiazhaike Village in Wuhe Township, and Xincheng Village in Jing'an Township. The high-level area was mainly distributed in the southern body areas such as Sanhe Village in Dongwan Town, Hejing Village in Wulan Town, Zhuangkou Village in Dalu Town, Gaoya Village in Beiwan Town, and Jiangtan Village in Pingpu Town. The high-level area showed an obvious " $\mathrm{T}$ " structure in space, namely the Yellow River as north-south development axis and Zuli River as the east-west development axis.

Rural ecological function was at a middle and high level. The average ecological function index was 0.15 , and the maximum is 0.27 . The ecological function index of the high-value and higher-value area ranged from 0.17 to 0.27 , which were mainly distributed in the southern main areas such as Hongliu Village in Dongwan Town, Xintian Village in Santan Town, Ershilipu Village in Wulan Town, and Shahe Village in Gaowan Town. Lowervalue areas ranged from 0.01 to 0.13 , mainly distributed in Batan Village, Peibao Village, and Renhe Village in Shimen Township, Hangou Village, Xinquan Village, Qingyang Village in Yongxin Township, and other northern enclaves. The spatial feature of rural ecological function showed as high in the south and low in the north. The main reasons are that the body area in the south has good irrigation conditions, villages there are mostly distributed in the Yellow River and Zuli River Valley, and the ecological environment is excellent. The ecological function level of Xinglong, Shuanglong, and Jing'an Village in the northern enclave was good, but the levels of other villages in the north were low due to the complex terrain and resource conditions.

The level of cultural function reflects the mentality of rural groups. The overall cultural function level of Jingyuan County was low, and the average of cultural function index was 0.17 . The high-value area of cultural function accounted for $14.20 \%$ of the total number of villages, mainly distributed in Hejing Village and Yingfang Village. The special feature of cultural function level presents the development structure with the county residence as the center and the other towns as the periphery. The enclaves of the north form a core of Shangtang Village, Baoan Village, and Dongsheng Village, and the main body in the south forms a cultural development and inheritance structure with the county as the center and the Yellow River as the axis. As an important old revolutionary base area, Yingfang Village is the core of the inheritance of Jingyuan Red Culture. The burial site culture, grotto culture, and military war culture contained in Hejing Village play a crucial role in improving the cultural function level of the southern region.

\subsubsection{Rural Development Level under Revised Evaluation}

The revised evaluation refers to an auxiliary judgment of the Ecological, Production and Living Spaces, and cultural function evaluation of the rural development level, and it can make up for the potential impact of the resource endowment and location conditions on the formation of rural development level, which are neglected in the functional evaluation (Figure 5). The level of rural development under the influence of resource endowment was high in the north and low in the south. The overall resource endowment was at a middle and low level, with an average of 0.20 and a maximum of 0.37 . The spatial distribution of high-value and high-value showed an obvious banded structure. The resource endowment of high-value and higher-value areas ranged from 0.21 to 0.37 , mainly concentrating on Liuchuan in the northern enclave and the northern intermountain basin, which forms the east-west banded development structure with Beitan Town, Wuhe Township, and Jing'an Township as the core. The high-value areas in the south were mainly distributed along the Yellow River valley. Dongwan Village, Shengli Village, Hongzui Village, Xitan Village, Gaoya Village, and Jinshan Village constitute the growth nodes of the belt development 
along the Yellow River valley in the south. The spatial distribution of low-value and lowervalue areas was relatively symmetrical, and the resource endowments in Pingchuan District as the symmetry axis were similar in the north-south distribution. The resource endowment in low-value area ranged from 0.01 to 0.15 , mainly distributed in the special, complex grasslands and woodlands of northern enclaves. The south area is mainly distributed in the unavailable, complicated meadows and hayfields.
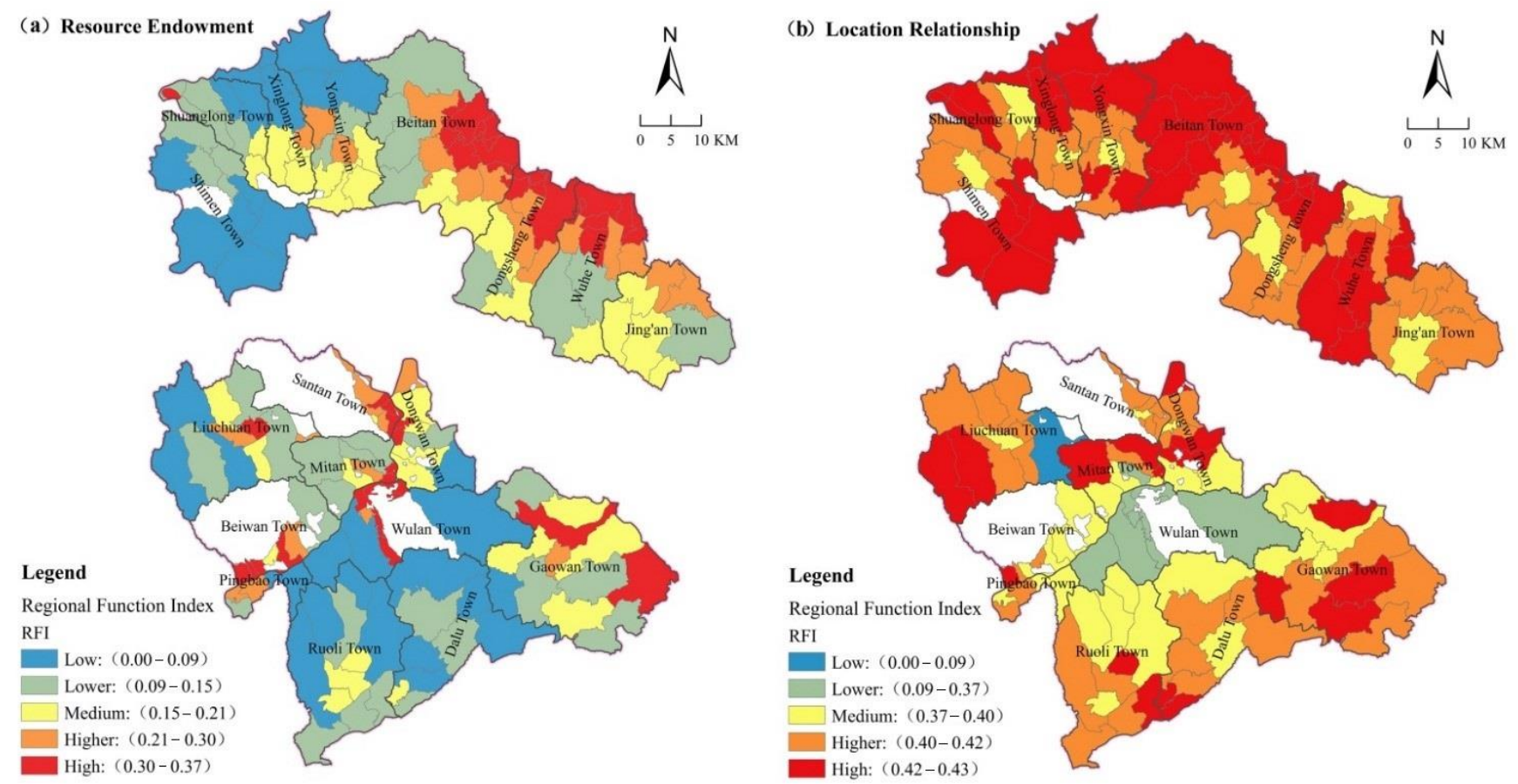

Figure 5. Rural development level under revised evaluation.

Location relationship analysis is to judge the development level of different villages under the guidance of location by judging the location relationship between different villages and central urban areas, towns, and large industrial and mining enterprises, which can effectively overcome the shortcomings of distance and linear factors in functional evaluation. Location relationship is a negative indicator of rural development evaluation whose value represented by its index is negatively correlated with rural development level. The high value shown in the figure only indicates that the village is far from the central urban area, towns, and industrial and mining enterprises, but its rural development level is opposite to the distance. The rural development level under the correction of location conditions shows the central-periphery structure centered on the urban areas. The areas with better rural development levels were mainly distributed around the central urban areas, such as Chengguan Village, Dongguan Village, Xiguan Village, Ershilipu Village, and Nanshanwei Village in Wulan Town. The low-value areas under the correction of location conditions were mainly distributed in Xinglong Township and Beitan Town in the northern enclave, such as Zhouwan Village, Batan Village, Yingping Village, and Lugou Village.

\subsection{Spatial Structure of Rural Development Level in Enclave Areas \\ 5.2.1. Global Autocorrelation}

The global Moran's I value of the regional function index under different evaluations in Jingyuan County was calculated by exploratory spatial statistical analysis combined with GeoDa software (Table 2). The global Moran's I value of the rural regional function index in Jingyuan County was greater than 0 , and the bilateral test $Z$ value was greater than the critical $Z$ value $(2.58)$ at 0.01 confidence level $[27,52,55]$, indicating that the level of rural development in Jingyuan County shows the characteristics of significant and positive spa- 
tial autocorrelation, that is, the distribution has significant spatial dependence, and obvious spatial agglomeration characteristics. The rural development level of Jingyuan County showed three agglomeration types in space. The first one is the strong agglomeration dominated by resource endowment and cultural function. The second one is the general agglomeration dominated by ecological and living functions. The last one is the weak agglomeration dominated by production function and location relationship. The Moran's I value of strong agglomeration was greater than 0.50 , indicating that living function and resource endowment are the dominant factors affecting the spatial agglomeration evolution of the rural development level, and are also the core variables leading to the spatial difference of the rural development level. The general Moran's I value of agglomeration ranged from 0.40 to 0.50 , indicating that the rural development level dominated by living and ecological functions have similar agglomeration characteristics in space. The weak agglomeration Moran's I value was less than 0.40 , indicating that there is an agglomeration dispersion distribution in space.

Table 2. Global Moran's I and parameter test.

\begin{tabular}{ccccccc}
\hline Regional Function & $\begin{array}{c}\text { Moran's } \\
\boldsymbol{I}\end{array}$ & $\boldsymbol{E}[\mathbf{I}]$ & $\boldsymbol{M}$ ean & $\boldsymbol{s} \boldsymbol{d}$ & $\boldsymbol{p}$-Value & Z-Value \\
\hline Production Function & 0.3906 & -0.006 & -0.0067 & 0.0512 & 0.0010 & 7.7627 \\
Living Function & 0.4513 & -0.006 & -0.0079 & 0.0490 & 0.0010 & 9.3806 \\
Ecological Function & 0.4427 & -0.006 & -0.0077 & 0.0506 & 0.0010 & 8.8936 \\
Cultural Function & 0.5039 & -0.006 & -0.0075 & 0.0487 & 0.0010 & 10.4972 \\
Resource Endowment & 0.5854 & -0.006 & -0.0065 & 0.0518 & 0.0010 & 11.4307 \\
Location Conditions & 0.3897 & -0.006 & -0.0061 & 0.0452 & 0.0010 & 8.7572 \\
\hline
\end{tabular}

\subsubsection{Local Spatial Autocorrelation}

Because the Moran scatter diagram does not provide the index of significance level, the local Moran's I value of each unit and the corresponding significance level were calculated by GeoDa software [52]. The villages with high significance level were extracted and the LISA agglomeration diagram of rural development level was drawn (Figure 6) to further analyze the evolution characteristics of rural development level in local space. From the perspective of local change characteristics, the rural development level of Jingyuan County showed a stable two-way agglomeration of high and low values, that is, high value and high value (H-H), low value and low value (L-L) agglomeration, and the spatial difference between high and low was obvious. H-H and L-L agglomerations indicated that there are similar evolution characteristics in the high-value areas of rural development level and other adjacent regional spaces, and the relationship between regions showed a significant hierarchical diffusion structure.

The rural development level of Jingyuan County not only presented two-way agglomeration of high and low values in space, but also formed a spatial agglomeration pattern dominated by different functions and factors. The number of $\mathrm{H}-\mathrm{H}$ agglomeration villages driven by cultural function was 21 , accounting for $12.43 \%$ of the total number of villages, mainly distributed in Hejing Village, Dongping Village, Dushi Village, Sanhe Village, Hongwan Village, and Dongsheng Village. The number of rural development level L-L agglomeration villages accounted for $14.20 \%$, mainly distributed in Kailong Village, Xinfeng Village and Sanxing Village in Jing'an Township, Yangsi Village, Jiazhaike Village in Wuhe Township, Jinchuan Village, and Zhangtan Village in Liuchuan Town. The two-way agglomeration of cultural functions emphasizes the importance of cultural representation forms such as cultural value, historical relics, and festival customs in the process of rural development. 

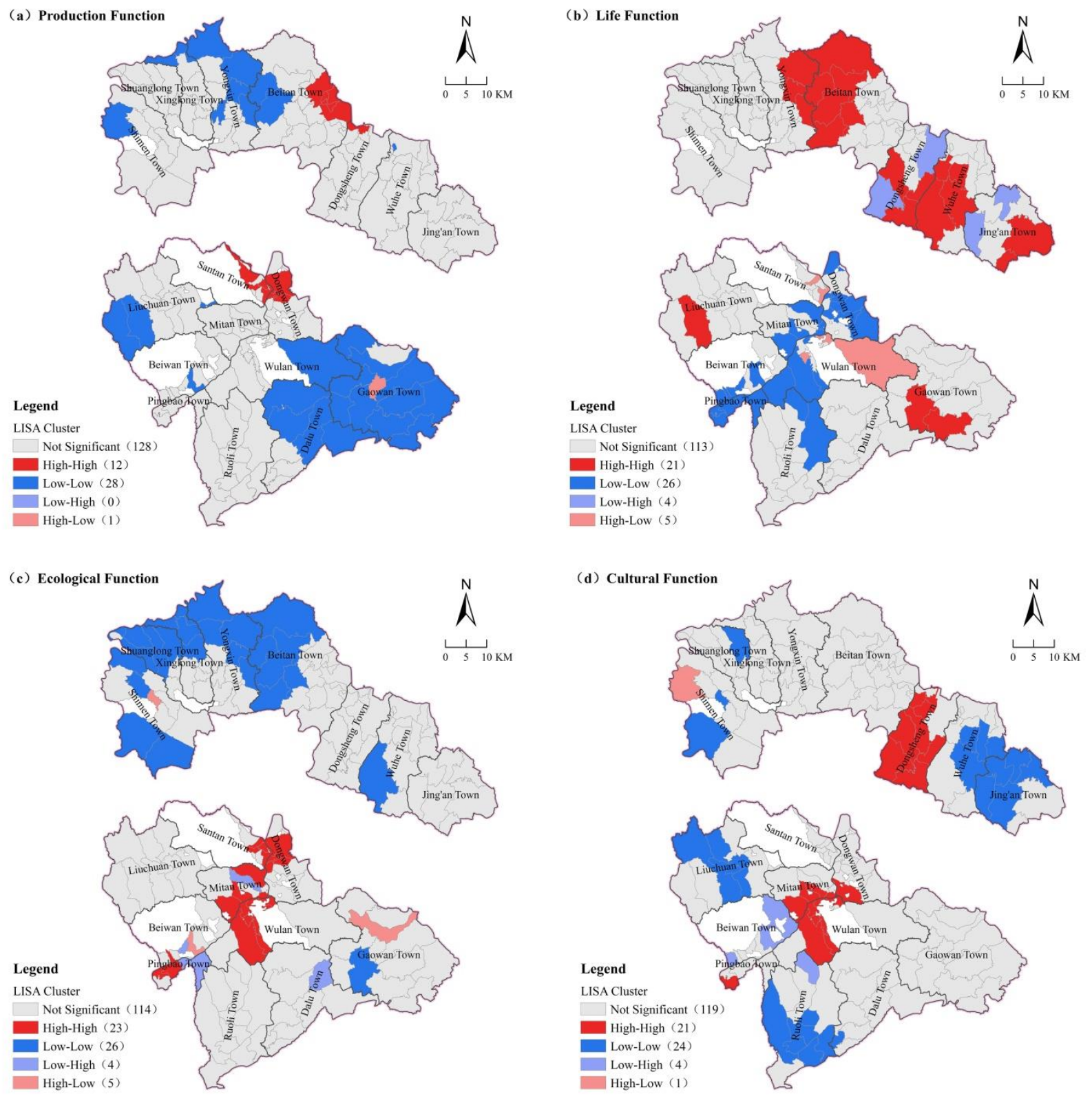

Figure 6. LISA distribution of rural development level in functional dimension.

The number of $\mathrm{H}-\mathrm{H}$ agglomeration villages under the influence of ecological function was 23 , accounting for $13.61 \%$ of the total number of villages, mainly distributed in the northern enclave of Shuanglong Township, Xinglong Township, Yongxin Township, and some villages in the eastern part of Beitan Town, which are concentrated in the grasslands and woodlands with diverse terrain and sufficient water resources. The number of L-L agglomeration villages was 26 , accounting for $15.38 \%$ of the total number of villages, mainly distributed in the valley plains where the Yellow River and Zuli River converge, such as Ershilipu Village, Xitan Village and Chengguan Village in Wulan Township, Dushi Village and Xiatan Village in Mitan Township, Nantou Village, and Hongliu Village in Dongwan Town, etc. The different agglomeration of ecological functions explains the internal mechanism of the disparity of rural development level in Jingyuan County, and demonstrates the multidimensional influence of ecological base and environmental protection on the rural development level.

The rural development level under the revised dimension shows the spatial agglomeration characteristics dominated by resource endowments (Figure 7). The number of 
$\mathrm{H}-\mathrm{H}$ agglomeration villages was 28 , accounting for $16.57 \%$ of the total number of villages, mainly distributed in Beitan Town and Dongsheng Township in the northern enclaves and the northern villages in Wuhe Township. The distribution of high-value agglomeration areas was mostly villages with diverse land types, gentle terrain, and which are adjacent to the villages in Xiangshan Township and Xingren Town in Ningxia Hui Autonomous Prefecture. The number of rural development level L-L agglomeration villages was 36, accounting for $21.30 \%$ of the total number of villages, mainly distributed in the villages in Shimen Township, Shuanglong Township, Xinglong Township, and Yongxin Township in the northern enclaves with weak resource conditions and backward economic development, and villages with single resource types and low value conversion such as Ruoli Township and Dalu Township in the main southern region. The agglomeration of resource endowments shows the spatial distribution characteristics of the dominant factors of rural development level. The rural development level of villages with various types of resources and good resource value conversion abilities was higher.
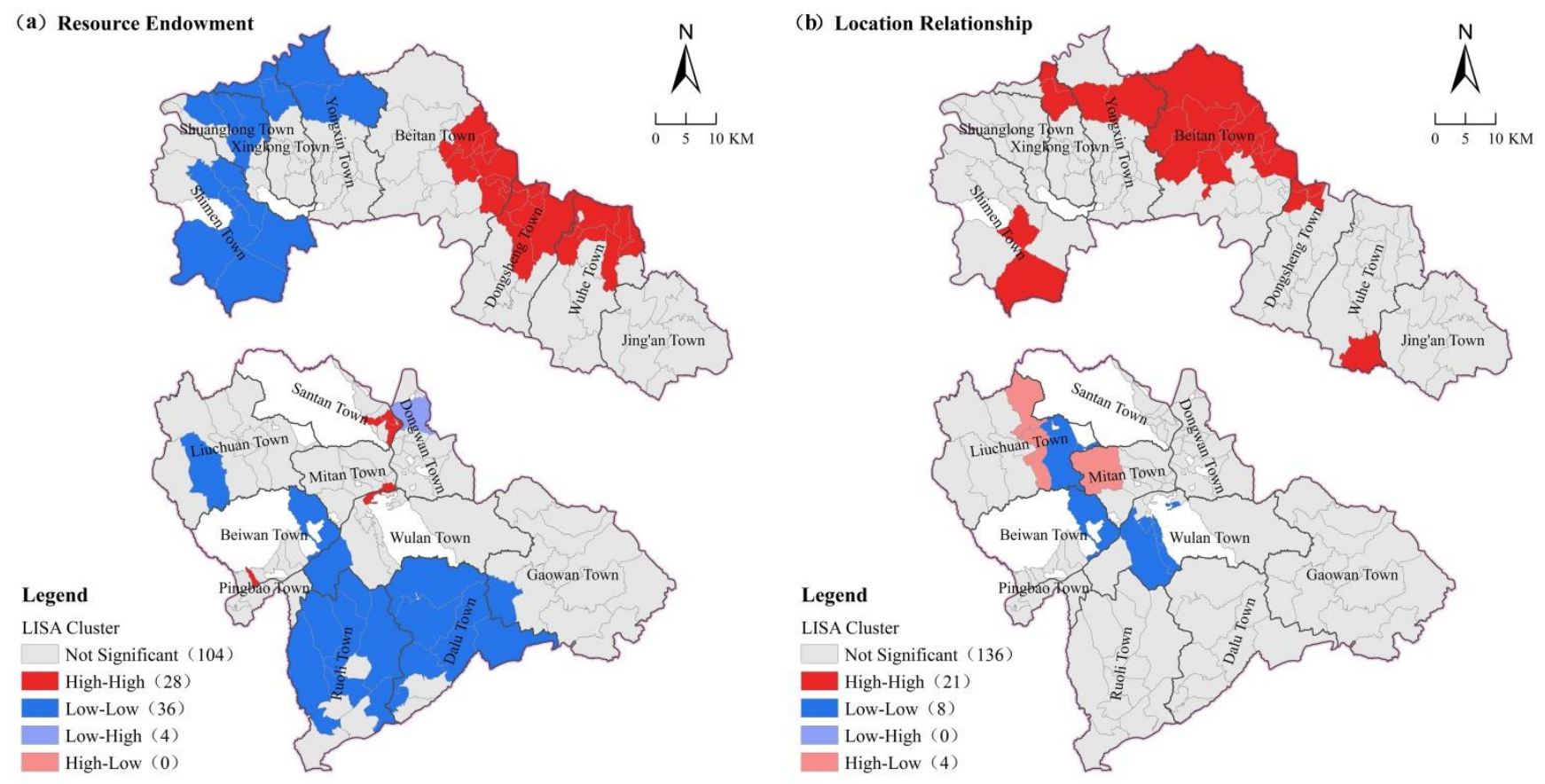

Figure 7. LISA distribution of rural development level in revised dimension.

\subsection{Spatial Structure of Rural Development Level in Enclave Areas}

\subsubsection{Development Type Identification}

Rural development has multiple functions, and there are significant differences in the forms and types of different functions [1,64]. From the perspective of "factor-structurefunction" correlation, the dominant factor of rural development type identification in enclave areas is determined, and the range of different identification factors is determined according to the difference characteristics of the calculated regional function index. In the identification factor of rural development type, due to the size of rural population that controls the change of living function factor and the aging degree of rural resident population, the distance between the location relationship and the central urban area and town area is a negative indicator. The larger the functional index is, the lower the level of rural development is. According to the above classification of the rural development level, the medium level value is eliminated from the defined "higher, high, medium, low and lower" level sequence, and the level of the dominant rural development type identification factor is determined to be "high and low". 
The " $4+10+6+2$ " system of rural development type identification in enclave areas was constructed by determining the identification factors of rural development type in enclave areas and combining the evaluation results with the actual situation of rural development in Jingyuan County (Table 3$) ;$ " 4 " is the primary classification of rural development, including agglomeration driving, integration and optimization, policy leading, and characteristic protection, while " 10 " is the secondary classification of rural development, including suburban integration, agglomeration centers, potential development, upgrades and optimization, remediation and restoration, and compound protection and so on, ten types in total. Additionally, " 6 " is the identification factors of rural development type, including production function, living function, and ecological function and so on, six in total; " 2 " is the judgment value to identify the secondary type of rural development, including high and low types. The identification of the type of rural development in the enclave areas is mainly through the regional function index value of the identification factor. According to the actual situation of rural investigation in Jingyuan County, the combination of high and low control identification factors was judged. Different types of villages were dominated by two types of identification factors. The indirect impact of some identification factors on specific types of villages can be ignored compared with the direct impact of the main control factor.

Table 3. Identification system of rural development types in enclave regions.

\begin{tabular}{|c|c|c|c|c|c|c|c|}
\hline \multirow{2}{*}{$\begin{array}{c}\text { First } \\
\text { Classification }\end{array}$} & \multirow{2}{*}{$\begin{array}{c}\text { Secondary } \\
\text { Classification }\end{array}$} & \multicolumn{6}{|c|}{ Recognition Factor } \\
\hline & & $\begin{array}{l}\text { Production } \\
\text { Function }\end{array}$ & $\begin{array}{c}\text { Living } \\
\text { Function }\end{array}$ & $\begin{array}{l}\text { Ecological } \\
\text { Function }\end{array}$ & $\begin{array}{l}\text { Cultural } \\
\text { Function }\end{array}$ & $\begin{array}{c}\text { Resource } \\
\text { Endowment }\end{array}$ & $\begin{array}{c}\text { Location } \\
\text { Conditions }\end{array}$ \\
\hline \multirow{2}{*}{$\begin{array}{l}\text { Agglomeration } \\
\text { Drive }\end{array}$} & Suburban Integration & High & - & - & - & - & Low \\
\hline & Agglomeration & - & - & - & - & High & High \\
\hline \multirow{2}{*}{$\begin{array}{l}\text { Integration and } \\
\text { Optimization }\end{array}$} & Potential Development & - & High & - & - & - & High \\
\hline & Promotion Optimization & - & High & - & - & Low & - \\
\hline \multirow{3}{*}{ Policy Leading } & Renovation & Low & - & - & - & High & - \\
\hline & Recession & Low & - & Low & - & - & - \\
\hline & Other general & - & - & Low & High & - & - \\
\hline \multirow{3}{*}{$\begin{array}{c}\text { Characteristic } \\
\text { Protection }\end{array}$} & Humanistic Protection & - & - & High & - & High & - \\
\hline & Natural Protection & - & - & - & High & High & - \\
\hline & Compound Protection & - & - & - & - & - & - \\
\hline
\end{tabular}

Note: The representative value of "_ has no direct impact on the type of rural development. "High" and "Low" represent the evaluation value of the indicators formed by the dominant rural types, and the range of high and low values is determined by removing the middle equivalence by the rural regional function index.

\subsubsection{Characteristics of Development Types}

The classification of rural development types plays an important role in integrating rural development resources and promoting the optimization of rural industrial structure [58]. The types of rural development in Jingyuan County mainly included agglomerationdriving, integrating-and-optimizing, policy-oriented, and typically-protecting types, which include several small classes (Figure 8). From the different types of rural characteristics and the changes of the regional function index, the rural development types of Jingyuan County are mainly divided into three levels, namely, the mutation with policy-oriented type as the core, the protection and development with both typically-protecting and integrating-andoptimizing type, and the steady development based on agglomeration-driving type. The number of policy-oriented mutation villages was a large proportion, accounting for $37.87 \%$ of the total number of villages. Living function and resource endowment are the core factors that dominate the change of rural types at the first level. The number of protection and development villages accounted for $46.75 \%$ of the total number of villages. Living, ecological, cultural functions, and resource endowments are the main factors affecting the change of rural types at the second level. Agglomeration-driving is the basic type of rural 
development in Jingyuan County. The comprehensive improvement of rural development level must be based on the large-scale agglomeration of industry, resources, and economy, so as to realize regional linkage and scale economic benefits. Agglomeration-driving type accounted for $15.38 \%$ of the total number of villages. Cultural function, resource endowment, and location relationship are important factors affecting the evolution of agglomeration-driving villages.
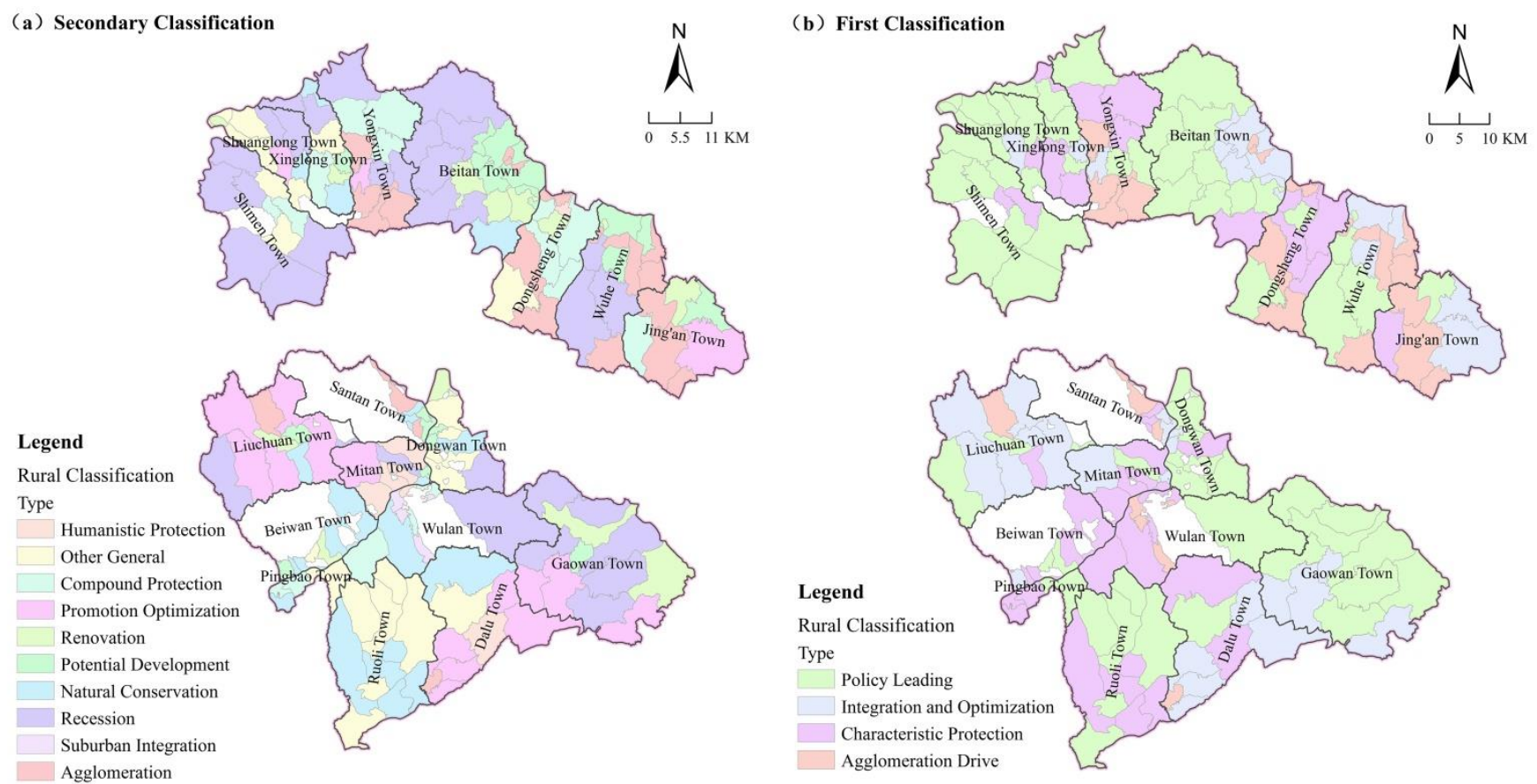

Figure 8. First classification and secondary classification of rural development in Jingyuan County.

In the secondary rural classification, the number of villages of the upgrading optimization and the recession-and-relocation accounted for $9.47 \%$ and $19.53 \%$ of the total villages respectively. The upgrading optimization villages were mainly distributed in Liuchuan Town, Mitan Township, Gaowan Town, and Dalu Township in the main southern region, such as Laiyao Village, Wujiadachuan Village, Liugou Village, Mazhai Village, and Shahe Village. Recession-and-relocation villages were mainly distributed in Shimen Township, Shuanglong Township, Beitan Town, and Wuhe Township in the northern enclave areas, and Gaowan Town in the southern main region, such as Citan Village, Yingping Village, Yaoliang Village, and Banwei Village. In the first-level classification, the policyoriented type and typically-protecting type were the dominant form of rural development in Jingyuan County. Policy-oriented villages were concentrated in regions with complex terrain conditions and difficult production, such as Xiaokou Village in Shimen Township, Beicheng Village in Shuanglong Township, Lugou Village in Beitan Town, and Wenya Village in Gaowan Town. The typically-protecting villages spatially presented a zonal distribution along the Yellow River and Zuli River Basin, mainly concentrated on areas with rich historical and cultural heritage and high ecological protection value.

\section{Discussion}

Enclave is an important unit of regional space at different scales [5]. Due to the adjustment of administrative divisions and the intervention of policy-leading, its area only retains administrative functions in space $[4,38]$. There are great differences in economy, culture, society, population, and beliefs between the two separated regions. In the new spatial unit, the rural areas in the enclave region are easily attracted by other regional resource conditions, cultural exchanges, industrial driving, and other factors, so it makes the separation between the enclave region and the main region serious, leads to industrial 
faults, and eventually results in the lag of regional economic development and the disorder of spatial structure [19]. Jingyuan County is a special impoverished county in the arid area of Northwest China [44]. On the one hand, it has obvious advantages in industrial development and industrial foundation, and benefits from various natural resources, good climate conditions, and sufficient water resources. On the other hand, it also faces some challenges. Firstly, the rural spatial layout is scattered. Secondly, most of the rural industrial structure is single. Thirdly, the population loss is serious. Finally, the aging phenomenon is intensified. Therefore, the opportunities and challenges in rural development coexist in Jingyuan County.

Selecting the factor-structure-function nexus perspective as the dominant theoretical framework of the development level of enclave-type rural areas is a further deepening of the evaluation of rural development level from a single perspective, scale, and method in traditional research [9]. At the same time, the rural development system from the perspective of factor-structure-function relations truly reflects the context and internal law of rural development and evolution in Jingyuan County. The rural development level of Jingyuan County under the influence of different factors was measured, although the variation characteristics of rural development level between the northern enclave area and the southern main area were preliminarily found. However, from the perspective of the characteristics and classification of rural development level, it is necessary to discuss two aspects. The first is the choice of rural development path in Jingyuan County under the implementation of a rural revitalization strategy and the second is the driving factors of spatial change of rural development level in the enclave-type region.

\subsection{Path Choice of Rural Development}

The choice of rural development path in the enclave region essentially answers the core question that needs to be solved to evaluate the level of rural development, that is, how should Jingyuan County develop in the future? The evaluation of rural development level is a scientific and reasonable analysis of the current situation and contradictions of rural development resources in space utilization [20,22]. Based on the calculated regional function index of rural development, the actual level of rural development within the region was judged, which provides references for the classification of rural development types and spatial judgment. The core goals of the rural revitalization strategy are reshaping the relationship between urban and rural areas, promoting the harmonious coexistence of man and nature, inheriting agricultural civilization, and promoting the structural reform of agricultural supply side [2]. To promote the overall improvement of rural development level, the implementation of the strategy in the specific village space should be more specific. The overall level of rural development in Jingyuan County is at a low-and-mid level, and the quality of rural development is generally not high. Taking the factor flow, structural change, and functional change in the process of rural development in Jingyuan County as the common thread, this paper determined the main path of rural development from the aspects of industry, population, tourism, land use, culture and ecology, etc. of different villages in Jingyuan County (Table 4), and formulated specific development strategies through relevant cases and the current situation of rural development in Jingyuan County. 
Table 4. Path selection of different rural development types.

\section{Types}

Essential Characteristics
It is mainly composed of suburban-fusion types and

Agglomeration Drive agglomeration center types. Such villages have a strong driving effect in space and can absorb peripheral resources to achieve economies of scale.
A2: Return Migration: On the basis of industrial agglomeration, promote the return of population, form a new population aggregation, build a new "modern farmers" system.

A3: Tourism Promoting: Build Jingyuan high-quality tourism routes, strengthen publicity and consumption guidance, and build a comprehensive, multi-leve rural tourism brand system. development type and promotion optimization type. Such villages have great potential in resource flow, and

Integration and Optimization new development vitality is needed in production, life, and ecology. Integrating the advantages of differen villages to achieve regional linkage and fine development.

B1:Land Use Optimization: Promote the efficient use of rural land and

implement the policy of "increase and decrease linked" to solving land restriction of rural construction development.
It is mainly composed of the potential
Path Selection

A1: Industrial Agglomeration: Based on the existing industrial foundation, we should create an industrial linkage mode to promote the expansion of the village industrial function and format.

\section{Concrete Tactics}

Case

Around facilities agriculture along the Yellow River, agriculture in the three irrigation districts, arid and semi-arid mountainous areas, cultural tourism along the Yellow River, park industry, etc., vigorously build a modern gricultural park, pastoral complex Jiangsu Province facility agriculture base as the core of the agricultural industry cluster.

Relying on diversified population

agglomeration, it introduces innovative scientific and technological factors to

$$
\text { the countryside, drives the }
$$

development of all kinds of talents in the village, brings urban population and maker culture to the village, and stimulates the diversified business development of the village.

Develop leisure tourism, and characteristic accommodation to promote the rural tourism cluster.

Create the Yellow River scenery tourism belt, Pingpu pastoral comprehensive experience area, and Dushi village rural tourism demonstration point

The land resources of some villages in

Liuchuan Town and Dalu Town were centralized remediation. The guide farmers centralized resettlement. To solve the characteristics of "more, Province
Shijiaao Village, Zhejiang Province construction of new rural communities

Xiangxiyi Village, Zhejiang residential areas and promote the distribution of land in pieces. 
Table 4. Cont.

Types Essential Characteristics

It is mainly composed of remediation type, recession-merging type, and other general types. Such villages have weak foundation, serious population loss, and single industrial structure. Policies are needed to intervene in the process of rural development and achieve spatial restructuring.

1: Spatial Reorganization: Optimizing the rational allocation of rural resources, and taking "migration", "integration", and "restoration" as means to affect the effective use of rural space.

\section{Path Selection}

D1: Cultural Activation: Explore the

It is mainly composed of humanistic protection, natural protection, and

compound protection. Humanities and

natural resources have obvious

characteristics, and have high

Characteristic Protection rotection value. It plays a core role in

promoting regional development. village village characteristic culture brand.

D2: Ecological Protection: Guided by ecological environment friendly and sustainable utilization of resources, establish a government-led, village participation, social support protection model.

\section{Concrete Tactics}

Case

For villages with small population, poor infrastructure, fragile ecological

environment, frequent natural disasters,

and major project construction needs, the reintegration of land, population, and means of production is promoted through policies such as excessive poverty alleviation and relocation, ecological remediation and restoration, ecological livable relocation, and rural agglomeration development relocation.

Integrate art into the countryside to revive local rural spirit and culture. Reflect on the homogeneous space brought by urbanization with nostalgia promoting people to look back at the countryside, re-experience the rural life form, and inherit the rural context.

Based on the protection of the ecological environment, making full use of environmental advantages, turning ecological environment advantages into economic advantages, relying on the Yellow River Basin and Zuli River Basin, and focusing on the development of the ecological economy.
Echigo-Tsumari, Japan

Minning Village, Ningxia

\section{Gaojiatang Village,} Zhejiang Province 


\subsection{Contributing Factors of Spatial and Temporal Differences in Rural Development Level}

The development and evolution of the rural regional system are the coefficient results of endogenous factors and exogenous factors [3,25]. Relevant systems and policies, which are considered as exogenous factors, affect the evolution of rural types by influencing the efficiency of distribution according to production factors such as population, land and capital, and etc. [23]. The contributing factors of rural development types are not only related to natural resources, human resources, industry and employment, information, science and technology, customs, and other factors, but are also closely related to the national regional development strategy and the development of surrounding areas. Jingyuan County is a special enclave region, whose core factor affecting the level and type of rural development is the adjustment of administrative divisions [36]. The change of administrative divisions makes the rural development level in south of Jingyuan County higher than that in north. The rural development conditions in the southern main area are good, the traffic is convenient, and the types of land resources are diverse [18,31], which makes the development level of most rural areas in its spatial unit higher than that in the northern enclave area. Affected by topography, traffic conditions, and population structure [62], the development of most rural areas of eight townships in north of Jingyuan County is at a low level. The administrative separation between the main area and the enclave area leads to a significant difference in the spatial distribution of rural development levels in different regions [22]. The high-value area and the low-value area of the rural development level are quite different. Although there are dense traffic lines and numerous river systems in the regional unit, there is a great distance between town and village, village and village, which hinders the spatial flow of resource factors and the transformation of industrial structure among different villages.

From the actual situation and evaluation results of rural development in Jingyuan County, the strong boundary of enclave makes its rural spatial structure gradually evolve from south to north. The adjustment of administrative divisions is the original factor of the low level of rural development in Jingyuan County [11], but the rural population size, degree of population aging, location conditions, natural environment, land resources, and other exogenous factors have a greater impact on rural development level in the enclave area. The high-value areas of rural development are mostly concentrated in river valleys, which have good cultivated land resources, and are distributed along the Yellow River and Zuli River Basin. The implementation of major treatment measures such as intensive utilization of rural land, integration of resource elements and restoration of ecological environment, and so on, has significantly improved the level of rural development in some villages with underdeveloped production and living conditions and fragile ecological environments, which is pushed forward by government-led policies such as relocation, village mergers, and other policies. It can be seen that natural resources, river systems, population size and structure, reformation of administrative division, and local policies are the leading factors of change in rural development level and type identification in enclave regions $[25,60]$, which affect the spatial distribution range and structural characteristics of the rural development level, and indirectly affect the effective implementation of rural revitalization strategies.

Overall, the measurement of rural development level in Jingyuan County is a scientific judgment on the rationality of the rural development process and path in typical areas. The evaluation index system of rural sustainable development level in enclave region was constructed from the perspective of "Factor-structure-function", and the rural development level of Jingyuan County was calculated by combining qualitative and quantitative methods. On the one hand, the evaluation results not only truly reflected the actual level of rural development in Jingyuan County in different periods, but also showed the limitations and problems in the implementation of the current rural revitalization strategy. The research results can not only guide the practice of rural development in poor areas at the theoretical level, but also provide a definite development path and direction for the future rural areas. The construction of index system from the perspective of "factor-structure-function" corre- 
lation further enriches the theoretical structure of rural development level measurement at home and abroad, and provides a new idea for the sustainable development evaluation of special geographical units from different perspectives, elements, and directions.

On the other hand, there are still many deficiencies in the selection of evaluation indicators, the collection of research data, and the selection of evaluation methods. The selection of evaluation indicators should fully consider the local identity of different groups, cultural heritage, industrial innovation, and other indicators. Interview questionnaires and sample selection need to be further supplemented and improved. The methods of measuring rural development level and analyzing spatial differentiation characteristics should be more scientific. Subsequent research will focus on the above aspects to supplement scientificity and integrity.

\section{Conclusions}

From the perspective of factor-structure-function correlation, the measurement index system of rural development level in enclave regions was constructed according to the actual rural development in Jingyuan County. The rural development level of Jingyuan County was measured by the rural development level index and the rural regional function index from the two dimensions which include functional evaluation and correcting evaluation. The characteristics of rural development level under the influence of production function, life function, ecological function, and cultural function were explored by means of the index of nearest neighbor points and exploratory spatial data analysis. According to the survey data which are based on territory development plan for villages and the actual situation of rural development in Jingyuan County, the dominant types of rural development in Jingyuan County were analyzed by the identification system of rural development types in the enclave region. The rural development types of Jingyuan County were divided into 4 first-class types and $10 \mathrm{~s}$-class types. The adjustment of administrative divisions, geographical location conditions, natural resource endowments, and socio-economic capital were the main factors affecting the spatial differences in the development level of different types of rural areas. Industrial agglomeration, population backflow, tourism promotion, and land use optimization are important paths to improve the sustainable development level of rural areas in enclaves. The following are the main conclusions:

1. The rural development of Jingyuan County is at a low-and-mid level, which is characterized by high in the south and low in the north. The southern main region forms a development zone based on the river valleys of the Yellow River Basin and Zuli River Basin. The high-value areas of rural development level in the northern enclave are concentrated in the valley plain which are located in the north of Quwu Mountain and Dasha River.

2. From the spatial evolution of rural development level under the function and correcting evaluation, the rural development level of Jingyuan County shows significant and positive spatial autocorrelation characteristics on the whole. The level of rural development has significant spatial dependence and obvious spatial agglomeration characteristics. The global space is characterized by strong agglomeration dominated by resource endowment and cultural function, general agglomeration dominated by life function and ecological function, and weak agglomeration dominated by production function and location relationship.

The local space is characterized by stable high value and high value $(\mathrm{H}-\mathrm{H})$, low value and low value (L-L) agglomeration, and the spatial difference is obvious. The northern enclave forms low-value and low-value agglomeration areas whose control cores are life and ecological functions. The southern main region forms high-value and high-value agglomeration areas dominated by living, ecological, and cultural functions as well as geographical conditions.

3. According to the classification of rural development types, the rural development types of Jingyuan County are mainly divided into four types: agglomeration-driving, integrating and optimizing, policy-leading, and protecting characteristic. The policy- 
leading and protecting characteristic are the dominant types of rural development in Jingyuan County. The rural development type in Jingyuan County forms a threedimensional structure, including the mutant type, which takes policy-leading as the core, the protection and development type with the combination of characteristic protection, integration, and optimization, and the steady development type based on agglomeration-driving.

Author Contributions: Conceptualization, J.Q. and W.L.; methodology, H.F.; software, J.Q. and H.F.; validation, J.Q., W.L. and Z.W.; formal analysis, J.Q.; investigation, Z.W. and H.F.; resources, Z.W.; data curation, J.Q.; writing-original draft preparation, J.Q.; writing—review and editing, J.Q. and W.L.; visualization, H.F.; supervision, W.L.; project administration, J.Q., W.L. and Z.W.; funding acquisition, J.Q., W.L. and H.F. All authors have read and agreed to the published version of the manuscript.

Funding: This research was funded by THE PROJECT OF NATIONAL SOCIAL SCIENCE FOUNDATION OF CHINA (No.14BSH029).

Data Availability Statement: Not applicable.

Conflicts of Interest: The authors declare no conflict of interest.

\section{References}

1. Liu, Y. The basic theory and methodology of rural revitalization planning in China. Acta Geogr. Sin. 2020, 75, 1120-1133.

2. Liu, Y.; Zhou, Y.; Li, Y. Rural regional system and rural revitalization strategy in China. Acta Geogr. Sin. 2019, 74, 2511-2528.

3. Li, Y.R.; Liu, Y.S.; Long, H.L.; Wang, J.Y. Local responses to macro development policies and their effects on rural system in China's mountainous regions: The case of Shuanghe Village in Sichuan Province. J. Mt. Sci. 2013, 10, 588-608. [CrossRef]

4. Bustos-Gallardo, B. The post 2008 Chilean Salmon industry: An example of an enclave economy. Geogr. J. 2017, 183, 152-163. [CrossRef]

5. Blanc, J. Enclaves of inequality: Brasiguaios and the transformation of the Brazil-Paraguay borderlands. J. Peasant Stud. 2015, 42, 145-158. [CrossRef]

6. Cloke, P. Rural Life-Styles: Material Opportunity, Cultural Experience, and How Theory Can Undermine Policy. Econ. Geogr. 1996, 72, 433-449. [CrossRef]

7. Cloke, P. Country backwater to virtual village? Rural studies and "the cultural turn". J. Rural Stud. 1997, 13, 367-375. [CrossRef]

8. Cloke, P.; Edwards, G. Rurality in England and Wales 1981: A replication of the 1971 index. Reg. Stud. 1986, 20, 289-306. [CrossRef]

9. Woods, M. Rural geography: Blurring boundaries and making connections. Prog. Hum. Geogr. 2009, 33, 849-858. [CrossRef]

10. Woods, M. Precarious rural cosmopolitanism: Negotiating globalization, migration and diversity in Irish small towns. J. Rural Stud. 2018, 64, 164-176. [CrossRef]

11. Midmore, P. Rural policy reform and local development programmes: Appropriate evaluation procedures. J. Agric. Econ. 1998, 49, 409-426. [CrossRef]

12. Cornwall, A.; Pratt, G. The use and abuse of participatory rural appraisal: Reflections from practice. Agric. Hum. Values 2011, 28, 263-272. [CrossRef]

13. Di Felice, V.; Batista, E.; Mancinelli, R.; Batista, J.G.F.; Campiglia, E. Rurality and agroecosystem sustainability: A case study at farm-field level in Terceira Island (Portugal) and in Viterbo Province (Italy). Renew. Agric. Food Syst. 2014, 29, 265-276. [CrossRef]

14. Jozsef, L. Interpreting rurality—Multidisciplinary approaches. Ter Tarsad. 2015, 29, $203-207$.

15. Lebedev, V.I.; Lebedeva, I.V.; Molchanenko, S.A.; Molchanenko, S.A.; Shuvaev, A.V. Economic and statistical evaluation of the level of sustainable development of rural areas. Res. J. Pharm. Biol. Chem. Sci. 2017, 8, 1841-1846.

16. Liu, Y.S.; Wang, G.G.; Zhang, F.G. Spatio-temporal Dynamic Patterns of Rural Area Development in Eastern Coastal China. Chin. Geogr. Sci. 2013, 23, 173-181. [CrossRef]

17. Long, H.L.; Zou, J.; Liu, Y.S. Differentiation of rural development driven by industrialization and urbanization in eastern coastal China. Habitat Int. 2009, 33, 454-462. [CrossRef]

18. Tu, S.; Long, H.; Zhang, Y.; Zhou, X. Process and driving factors of rural restructuring in typical villages. Acta Geogr. Sin. 2019, 74, 323-339.

19. Desjeux, Y.; Dupraz, P.; Kuhlman, T.; Paracchini, M.L.; Michels, R.; Maigne, E.; Reinhard, S. Evaluating the impact of rural development measures on nature value indicators at different spatial levels: Application to France and The Netherlands. Ecol. Indic. 2015, 59, 41-61. [CrossRef]

20. Huang, X.H.; Cai, B.Q.; Li, Y.L. Evaluation Index System and Measurement of High-quality Development in China. Rev. Cercet. Interv. Soc. 2020, 68, 163-178. [CrossRef] 
21. Li, D.W.; Chen, J.B.; Qiu, M.L. The Evaluation and Analysis of the Entropy Weight Method and the Fractional Grey Model Study on the Development Level of Modern Agriculture in Huizhou. Math. Probl. Eng. 2021, 2021, 8.

22. Mikus, O.; Franic, R.; Grgic, I. The evaluation of rural competitiveness in creating a policy of rural development in Croatia. J. Food Agric. Environ. 2012, 10,962-969.

23. Zhang, M.D.; Wang, X.; Zhang, Z.X.; Zhao, X.L. Assessing the Potential of Rural Settlement Land Consolidation in China: A Method Based on Comprehensive Evaluation of Restricted Factors. Sustainability 2018, 10, 20. [CrossRef]

24. Halfacree, K.H. Locality and social representation: Space, discourse and alternative definitions of the rural. J. Rural Stud. 1993, 9, 23-37. [CrossRef]

25. Li, Y.R.; Li, Y.; Fan, P.C.; Long, H.L. Impacts of land consolidation on rural human-environment system in typical watershed of the Loess Plateau and implications for rural development policy. Land Use Pol. 2019, 86, 339-350.

26. Li, Y.R.; Long, H.L.; Liu, Y.S. Spatio-temporal pattern of China's rural development: A rurality index perspective. J. Rural Stud. 2015, 38, 12-26. [CrossRef]

27. Yang, Y.Y.; Bao, W.K.; Liu, Y.S. Coupling coordination analysis of rural production-living-ecological space in the Beijing-TianjinHebei region. Ecol. Indic. 2020, 117, 13. [CrossRef]

28. Wang, Y.Q.; Guo, X.Y.; Liu, H.M. Synthetic evaluation of new socialist countryside construction at county level in China. China Agric. Econ. Rev. 2011, 3, 383-401. [CrossRef]

29. He, T.Q.; Qiao, W.F.; Jia, K.Y.; Chai, Y.B.; Hu, Y.; Sun, P.; Wang, Y.H.; Feng, T. Selecting Rural Development Paths Based on Village Multifunction: A Case of Jingjiang City, China. Complexity 2020, 2020, 15. [CrossRef]

30. Hu, H.Q.; Ma, Y.; Wu, S.J. Fuzzy comprehensive evaluation on high-quality development of China's rural economy based on entropy weight. J. Intell. Fuzzy Syst. 2020, 38, 7531-7539. [CrossRef]

31. Xiang, C.; Qin, J.X.; Yin, L. Study on the rural ecotourism resource evaluation system. Environ. Technol. Innov. 2020, 20, 14. [CrossRef]

32. Gu, X.K.; Xie, B.M.; Zhang, Z.F.; Guo, H. Rural multifunction in Shanghai suburbs: Evaluation and spatial characteristics based on villages. Habitat Int. 2019, 92, 10. [CrossRef]

33. Harrington, L.M.B. Alternative and Virtual Rurality: Agriculture and the Countryside as Embodied in American Imagination. Geogr. Rev. 2018, 108, 250-273. [CrossRef]

34. Hu, X.; Li, H.; Zhang, X.; Yuan, Y. On the re-cognition of rural definitions. Acta Geogr. Sin. 2020, 75, 398-409.

35. Yuan, Y.; Zhang, X.; Li, H.; Hu, X. Rural Space Transition in Western Countries and Its Inspiration. Sci. Geogr. Sin. 2019, 39, $1219-1227$.

36. Li, Z.; Zhang, X.; Li, H.; Fan, L. Research on Rurality at Village Scale and Rural Development Model: A Case of Jintan City, Jiangsu Province. Sci. Geogr. Sin. 2017, 37, 1194-1202.

37. Abreu, I.; Nunes, J.M.; Mesias, F.J. Can Rural Development Be Measured? Design and Application of a Synthetic Index to Portuguese Municipalities. Soc. Indic. Res. 2019, 145, 1107-1123. [CrossRef]

38. Bristow, G.; Cowell, R.; Marsden, T. Tensions, limits and potentials-Evaluating rural development policies in Scotland. Eur. Urban Reg. Stud. 2001, 8, 235-252. [CrossRef]

39. Cei, L.; Stefani, G.; Defrancesco, E.; Lombardi, G.V. Geographical indications: Indications: A first assessment of the impact on rural development in Italian NUTS3 regions. Land Use Pol. 2018, 75, 620-630. [CrossRef]

40. De Lotto, R.; Cattaneo, T.; Giorgi, E.; Venco, E.M. Coherences and Differences among EU, US and PRC Approaches for Rural Urban Development: Interscalar and Interdisciplinary Analysis. Sustainability 2017, 9, 26. [CrossRef]

41. Diaz-Puente, J.M.; Montero, A.C.; Carmenado, I.D. Empowering communities through evaluation: Some lessons from rural Spain. Community Dev. J. 2009, 44, 53-67. [CrossRef]

42. Freshwater, D. Vulnerability and Resilience: Two Dimensions of Rurality. Sociol. Rural. 2015, 55, 497-515. [CrossRef]

43. Mao, Q.; Peng, J.; Liu, Y.; Wu, W.; Zhao, M.; Wang, Y. An ecological function zoning approach coupling SOFM and SVM: A case study in Ordos. Acta Geogr. Sin. 2019, 74, 460-474.

44. Ma, L.B.; Chen, M.M.; Fang, F.; Che, X.L. Research on the spatiotemporal variation of rural-urban transformation and its driving mechanisms in underdeveloped regions: Gansu Province in western China as an example. Sust. Cities Soc. 2019, 50, 13. [CrossRef]

45. Ottomano Palmisano, G.; Govindan, K.; Boggia, A.; Loisi, R.V.; De Boni, A.; Roma, R. Local Action Groups and Rural Sustainable Development. A spatial multiple criteria approach for efficient territorial planning. Land Use Pol. 2016, 59, 12-26. [CrossRef]

46. Madsen, L.M.; Adriansen, H.K. Understanding the use of rural space: The need for multi-methods. J. Rural Stud. 2004, 20, 485-497. [CrossRef]

47. Martire, S.; Tuomasjukka, D.; Lindner, M.; Fitzgerald, J.; Castellani, V. Sustainability impact assessment for local energy supplies' development-The case of the alpine area of Lake Como, Italy. Biomass Bioenerg. 2015, 83, 60-76. [CrossRef]

48. Michalek, J.; Zarnekow, N. Application of the Rural Development Index to Analysis of Rural Regions in Poland and Slovakia. Soc. Indic. Res. 2012, 105, 1-37. [CrossRef]

49. Overvag, K.; Berg, N.G. Second Homes, Rurality and Contested Space in Eastern Norway. Tour. Geogr. 2011, 13, 417-442. [CrossRef]

50. Sayadi, S.; Roa, M.C.G.; Requena, J.C. Ranking versus scale rating in conjoint analysis: Evaluating landscapes in mountainous regions in southeastern Spain. Ecol. Econ. 2005, 55, 539-550. [CrossRef] 
51. Li, H.Q.; Guo, T.H.; Nijkamp, P.; Xie, X.L.; Liu, J.J. Farmers' Livelihood Adaptability in Rural Tourism Destinations: An Evaluation Study of Rural Revitalization in China. Sustainability 2020, 12, 16. [CrossRef]

52. Wu, X.; Cui, P. A Study of the Time-Space Evolution Characteristics of Urban-Rural Integration Development in a Mountainous Area Based on ESDA-GIS: The Case of the Qinling-Daba Mountains in China. Sustainability 2016, 8, 17. [CrossRef]

53. Siciliano, G. Urbanization strategies, rural development and land use changes in China: A multiple-level integrated assessment. Land Use Pol. 2012, 29, 165-178. [CrossRef]

54. Yoder, L.S.M. The development eraser: Fantastical schemes, aspirational distractions and high modern mega-events in the Oecusse enclave, Timor-Leste. J. Polit. Ecol. 2015, 22, 299-321. [CrossRef]

55. Ying, L.X.; Shen, Z.H.; Chen, J.D.; Fang, R.; Chen, X.P.; Jiang, R. Spatiotemporal patterns of road network and road development priority in three parallel rivers region in Yunnan, China: An evaluation based on modified kernel distance estimate. Chin. Geogr. Sci. 2014, 24, 39-49. [CrossRef]

56. Long, D.; Li, T.; Yu, Z.; Meng, H. Assessment of Rural Development Level and Mechanism Analysis Based on MicroPerspectiveA Case Study of the Demonstration Area of Urban-Rural Intergration in Gaoling County of Shaanxi Province. Eonomic Geogr. 2013, 33, 115-121.

57. Zalizko, V.D.; Lutcenko, I.O.; Martynenkov, V.I. Evaluation of Sustainable Rural Development of Ukraine: Regional Aspect. Sci. Bull. Polissia 2017, 1, 182-188. [CrossRef]

58. Jez Rogelj, M.; Mikus, O.; Zrakic Susac, M.; Hadelan, L. Selection of Social Indicators for Measuring Sustainable Rural Development. Sci. Pap.-Ser. Manag. Econ. Eng. Agric. Rural Dev. 2020, 20, 295-305.

59. Diez, M.A.; Izquierdo, B.; Malagon, E. Increasing the Use of Evaluation Through Participation: The experience of a rural sustainable development plan evaluation. Environ. Policy Gov. 2016, 26, 366-376. [CrossRef]

60. Liu, Y.Q.; Liu, J.; Guo, C.; Zhang, T.T.; Wang, A.L.; Yu, X.Y. Identification of Villages' Development Types Using a Comprehensive Natural-Socioeconomic Framework. Sustainability 2021, 13, 20.

61. Ilskog, E.; Kjellstrom, B. And then they lived sustainably ever after? Assessment of rural electrification cases by means of indicators. Energy Policy 2008, 36, 2674-2684. [CrossRef]

62. Park, D.B.; Yoon, Y.S. Developing Sustainable Rural Tourism Evaluation Indicators. Int. J. Tour. Res. 2011, 13, 401-415. [CrossRef]

63. Gao, X.; Wang, K.; Lo, K.; Wen, R.Y.; Mi, X.T.; Liu, K.M.; Huang, X.X. An Evaluation of Coupling Coordination between Rural Development and Water Environment in Northwestern China. Land 2021, 10, 14. [CrossRef]

64. Cheng, M.Y.; Liu, Y.S.; Zhou, Y. Measuring the symbiotic development of rural housing and industry: A case study of Fuping County in the Taihang Mountains in China. Land Use Pol. 2019, 82, 307-316. [CrossRef] 